канд. пед. наук, доцент кафедры русского языка и литературы Восточного института - Школы региональных и международных исследований ДВФУ (г. Владивосток)

Электронная почта: panchenko.tf@dvgu.ru

\title{
Рассказ И. А. Бунина «Тёмные аллеи» и стихотворение Н. П. Огарёва «Обыкновенная повесть»: интертекстуальный диалог
}

Рассказ анализируется в контексте с прецедентным тек- И. Бунин «Тёмные стом - стихотворением Н. П. Огарёва "Обыкновенная по- аллеи», весть». Отмечены реминисценции на уровне названия, со- Н. Огарёв бытия встречи - расставания - воспоминания, отношения «Обыкновенная героев к двоякой природе образа "тёмных аллей». Проана- повесть», лизировано развитие диалектического сочетания любви и интертекст, несчастья, быта и бытия. Выявлено художественное своеобразие рассказа Бунина: мотивное построение сюжета, бинарная оппозиция системы персонажей, особенность художественного времени и пространства. Доказано, что интертекстуальный диалог произведений разных литературных родов позволяет обнаружить в исследуемом произведении новые философские смыслы.

Цикл рассказов И. Бунина «Тёмные аллеи» - явление довольно изученное. В последнее десятилетие XXI в. возрос интерес к интертекстуальной основе как сборника в целом, так и отдельных его рассказов. Проблема реминисцентно-аллюзивных перекличек исследуется как известными, так и молодыми учеными: Е. Е. Анисимовой, Е. С. Анненковой [2]; О. В. Богдановой, Ц. Лю [5]; Т. В. Марченко [9]; Н. В. Пращерук [12]; Т. М. Бонами [6]; Е. Пономарёвым [11]. О книге И. А. Бунина «Тёмные аллеи» как метажанровом единстве мы писали [10]. Данная статья является её логическим продолжением.

Рассказ «Тёмные аллеи», ставший заглавием цикла (книги, сборника), кажется исследованным с разных сторон. Однако обращение к нему всякий раз открывает, говоря словами М. Бахтина, «новые ... стороны, новые смысловые глубины» $[2$, с. 335]. Цель данной статьи - рассмотреть интертекстуальный диалог (реминисценции) лирического рассказа Бунина с повествовательным стихотворением Н. П. Огарёва «Обыкновенная повесть» как смыслообразующий сюжетный лейтмотив. Л. С. Выготский отмечал, что название «намечает ту доминанту, которая определяет собой всё построение» сложного целого и которая несёт в себе "раскрытие самой важной темы» [8, с. 200].

Рассказ «Тёмные аллеи» из сборника эмигрантского периода с одноимённым названием - один из тридцати восьми шедевров о вечном человеческом чувстве - любви. Он краток, как и тот миг, когда герои были вместе. Встретившись на дороге, вспомнив былое, они разошлись - такова фабула рассказа. Ничего выдающегося. Ничего особенного. Обыкновенная

\section{диалог,} реминисценция, фабула/сюжет, мотив
Для иитирования:

Панченко Т. Ф. Рассказ

И. А. Бунина «Тёмные аллеи»

и стихотворение Н. П. Огарёва «Обыкновенная повесть»: интертекстуальный диалог // Известия Восточного института. 2020. № 3 . C. 31-40. doi: dx.doi. org/10.24866/2542-1611/2020 $3 / 31-40$ 
история. Как стихотворение Н. П. Огарёва «Обыкновенная повесть» (1842), аллюзия на которое составляет глубинный, сюжетно-композиционный смысл произведения и является его внутренним лейтмотивом. Указание на него содержится в воспоминаниях писателя: «Перечитывал стихи Огарёва и остановился на известном стихотворении: «Была чудесная весна!/Они на берегу сидели,/Во цвете лет была она,/Его усы едва чернели.../Кругом шиповник алый цвёл,/ Стояла тёмных лип аллея...» Почему-то представилось то, что начинается мой рассказ - осень, ненастье, большая дорога, тарантас, в нём старый военный... Остальное как-то само собой сложилось, выдумалось очень неожиданно...» [цит. по 15]. Данное стихотворение необычайно важно для понимания смысла титульного рассказа.

Название «Обыкновенная повесть» соответствует содержанию: его можно пересказать, данное стихотворение фабульно в своей основе. Перед нами действительно история обыкновенная: весна, молодость, первая любовь, а после - реальная светская жизнь («...Она была женой другого,/ Он был женат, и о былом/ В помине не было и слова»). Рассказ И. А. Бунина представляет собой параллель данной истории, наполняя «обыкновенную» фабулу лирическим содержанием. Огарёв сосредоточил внимание на повествовании, Бунин раскрыл психологический «портрет» события. Огарёва интересует одно из ряда привычных в «светской» жизни явлений в прошлом и его последствия, Бунина - из ряда вон выходящее, а именно - случайный миг встречи, показавший и поэзию прежних чувств, и прозу настоящего и будущего. Стихотворение содержит опорные слова-мотивы, дублирующиеся в рассказе: пейзаж, портреты героев, намёк на их судьбу. Стихотворение фабульно, в нём преобладает взгляд автора от третьего лица. Рассказ в своей основе содержит ослабленную фабулу, он состоит из диалога двух героев, причём диалога глубоко конфликтного характера. Это противоречие не внешнего, эксплицитно «видимого» содержания, а психологического, имплицитно скрытого - «невидимого». Оттолкнувшись от стихотворения, Бунин сталкивает две точки зрения: «всё проходит, всё забывается» (Николай) и «всё проходит, да не всё забывается» (Надежда) [1, с. 13]. Уже из этих оппозиций видна причина невозможности "смеяться хладнокровно», как решён конфликт в стихотворении: Бунин усложняет схематизм стихотворного («рассказового») повествования в соответствии со своим мировоззрением, в частности - со взглядом на любовь. Причину сюжетного бесфабульного столкновения следует искать и в характерах героев, и в обстоятельствах их жизни, и в авторской оценке.

Образ, вынесенный в название рассказа и цикла, тоже из стихотворения. Только в стихотворении время действия - «чудесная весна», а в рассказе - «холодное осеннее ненастье». «Тёмные аллеи» сохраняют тайну любви только тогда, когда для обоих «река...тиха, ясна», когда «дол спокойно пышет», «шиповник алый» цветёт. Через тридцать лет на эти природные красоты герои, да и автор, смотрят по-иному, поэтому в рассказе появляются важные детали: дорога, изрезанная «многими чёрными колеями», «тёмноликий», похожий на «старинного разбойника» мужик» на козлах тарантаса, - и тёмные аллеи уже не манят к себе, а страшат. Жизнь раздвигает границы человеческого видения, и «язык любви первоначальной» ощущается лишь в воспоминаниях «на дне души печальной». 
Неуютная дорога, тряский тарантас, осенняя промозглость резко контрастируют с тёплой, сухой, чистой горницей, «где можно...отдохнуть и переночевать, пообедать или попросить самовар». Рассказ начинается с антитезы, которую можно прочесть как «искушение». Это один из тех жизненных случаев, который заставляет человека делать выбор, это его перепутье, его перекрёсток. «Камо грядеши?»

Он и она. Николай и Надежда. Он вечный путник, не случаен выбор имени героя: Никола Угодник - покровитель всех странствующих; отчество «Алексеевич» намекает на биографическую основу образа, которую обнаруживаем в книге в целом. Николай Алексеевич, «старик-военный», «ещё чернобровый» (отсылка к строке стихотворения «его усы едва чернели»), но уже «с белыми усами». У него «красивое удлинённое лицо с тёмными глазами» $[1$, с. 9]. Надежда - хозяйка постоялого двора, темноволосая, «тоже чернобровая», «тоже ещё красивая не по возрасту», «похожая на пожилую цыганку» [1, с. 10]. Нельзя не заметить сходства в их внешности (чернобровые, красивые). Дважды повторенное «тоже» в её портретной характеристике явно сопоставительного характера. Это предпосылка назревающего столкновения. Герои внешне равны, стоят друг друга. Но герой - приезжий (временный) человек, гость, а она хозяйка (постоянный). Она в системе образов главная, и она будет его эмоционально подавлять: ей принадлежит ведущая роль в диалоге, она его инициатор. Надежда оправдывает своё имя: замуж не выходила, ждала своего Николая. И это не случайно, так как женщина в мире Бунина очень важна: её чувства, её состояние (постижение мира всеми органами чувств свойственно героям Бунина, как, кстати, и самому автору) в центре внимания автора. Герой-мужчина лишь причина её волнений, эмоций, порой герои-мужчины вообще обозначены у Бунина схематично (например, в рассказах книги «Смарагд», «Волки», «Сто рупий»).

Оба персонажа не романтические, не исключительные личности. В манере Николая Алексеевича говорить подчёркнута неприязненность, во взгляде - строгость. Портрет Надежды контрастирует с не совсем привлекательными подробностями («полная, с большими грудями под красной кофточкой, с треугольным, как у гусыни, животом под чёрной шерстяной юбкой»). Ожидание чего-то таинственного, заданного предыдущими деталями: ночь, неизвестная станция, Он и Она, - исчезает.

Атмосфера рассказа создана тёмными красками и размыта некоторыми светлыми тонами. Перед нами два цветовых пространства: улица, дорога, грязь - и тёплая, сухая, чистая горница. Каждый из героев принадлежит к одному из пространств (Николай Алексеевич дорога, Надежда - горница). Особенно ярко представлено описание дороги: «В холодное осеннее ненастье, на одной из больших тульских дорог, залитой дождями и изрезанной чёрными колеями, к длинной избе <...> подкатил закиданный грязью тарантас» [1, с. 9]. В этом пейзаже выразилось не только общее настроение рассказа («холодное», «осеннее», «закиданный грязью»), но и скрытый намёк на то, что будет происходить (возникнет «ненастье» между героями, конфликт). В описании находим и образное отражение психологического портрета героя («на одной из $<\ldots>$ дорог $<\ldots>$ изрезанной чёрными колеями»). Оно контрастирует с описанием горницы, с интерьером: «В горнице было тепло, сухо и опрятно: новый золотистый образ в левом углу, 
под ним покрытый чистой суровой скатертью стол, за столом чисто вымытые лавки...» [1, с. 9-10]. Теплота горницы ощущается физически, это тепло печи, но это не душевная теплота хозяйки. Если обратиться к стихотворению Н. П. Огарёва, то увидим резкий контраст между его весенним, тёплым пейзажем и тем, что рисует Бунин, словно показывая изнаночную сторону стихотворного мира.

Из диалога героев мы узнаём историю их любви, их обыкновенную повесть. Если в стихотворении герои равноправны в плане социальном и возрастном, то здесь неравенство налицо: барин и бывшая крепостная с разницей в возрасте. Он «бессердечно» бросил Надежду, а ведь она отдала ему «свою красоту, свою горячку» [1, с. 12-13]. И за это они оба страдают. Здесь появляется мотив рока, судьбы: «Что кому бог даёт, - констатирует Надежда. - Молодость у всякого проходит, а любовь - другое дело» $[1$, с. 12]. Тот же мотив слышится и в данном диалоге: « - ...Боже мой, как странно! - Что странно, сударь? - Но всё, всё... Как ты не понимаешь!» [1, с. 12]. Николай и не подозревал о возможной встрече, он оставил всё в прошлом, Надежда же напротив - держа в сердце обиду, продолжала нести бремя разбитой жизни. Этим-то и подавляет героиня - своей омертвелостью («мёртвых с погоста не носят») [1, с. 13], сухой хозяйственностью («А хозяйствовать я люблю») [1, с. 10]. Герой изображён более живым, его быстрая смена эмоционального состояния отражается внешне: «взгляд вопрошающий, строгий и вместе с тем усталый», «неприязненно крикнул», «быстро выпрямился, раскрыл глаза и покраснел», «решительно заходил», «покраснел до слёз», «болезненно усмехнулся», «стыдился своего стыда» $[1$, с. 9, 10, 13].

Световое решение обоих произведений также различно: если в стихотворении идёт движение от света («вставало солнце», «чудесная весна», «при утренней встрече») к темноте, забвению («могли смеяться хладнокровно», «и темно осталось, для людей закрыто»), то в рассказе свет воспоминания появляется как редкий проблеск, невольный луч среди непроглядной тьмы. Отсюда и кольцевая композиция рассказа (дорога - горница - дорога): здесь не дорога, по которой едет человек куда-то, слово не в прямом значении, а в переносном - дорога как символ жизненного пути. Остановка на постоялом дворе и неожиданная встреча потревожили израненную душу человека, чья жизнь тоже изрезана «глубокими чёрными колеями». И после этой вспышки человек продолжает свой путь: «Погоняй, пожалуйста, как бы не опоздать нам к поезду...» [1, с. 14].

Женщина, знающая себе цену, но понимающая своё место, вначале ведёт себя с Николаем как и с любым другим проезжающим, уважительно приветствуя гостя., задаёт дежурный вопрос о самоваре. Бунин сознательно не сопровождает их последующий диалог авторскими ремарками, комментариями к репликам. Автор наблюдает за изменением психологического состояния героев. Он - сначала «мельком взглянул» на неё, «отрывисто, невнимательно ответил». Она - «всё время пытливо смотрела на него, слегка щурясь» - концентрировала внимание, вглядывалась, припоминая, прежде чем назвать его по имениотчеству. Он - «быстро выпрямился [его здесь знают, он офицер, он не имеет права выказывать усталость], «раскрыл глаза и покраснел». Одно предложение - а как много говорит! Он - человек совестливый, памятливый. Автор постоянно подчёркивает это повторами одноко- 
ренных слов: «краснея сквозь седину», «покраснел до слёз». Через отрывочные ответы мы узнаем о пылкой юношеской любви молодого барина и крепостной девушки. Как обычно, Бунин использует композиционный «минус-приём» (так называет эту стилевую особенность известный учёный-психолог Л. С. Выготский), не описывая подробно ситуацию, а лишь «вспоминая» о ней. Мы, читатели, восстанавливаем в своём воображении картины любви, учитывая эмоциональное состояние и отношение героев к этому событию-воспоминанию. Для Надежды - эта любовь единственная, непреходящая: «Сколько ни проходило времени, всё одним жила». Для Николая - «Всё проходит... Любовь, молодость - всё, всё. История пошлая, обыкновенная».

В связи с диалоговым построением выявляется и необычный хронотоп рассказа. Разговор героев несёт не только идейно-эмоциональную нагрузку, но и помогает восстановить фабулу, которая схематически может быть извлечена из стихотворения. Важным фактором является воспоминание как переход из настоящего в прошлое: «ведь при господах выросла», «Сколько лет мы не видались?», «Небось помните, как я вас любила», «очень бессердечно вы меня бросили», «Ах, как хороша ты была! - Помню, сударь. Были и вы отменно хороши». В то же время прошлое переходит в настоящее на эмоциональночувственном уровне героев: «Ведь было время, Николай Алексеевич, когда я вас Николенькой звала, а вы меня - помните как?» - «Как же можно такое забыть», «Как не было у меня ничего дороже вас на свете в ту пору, так и потом не было», «Никогда я не был счастлив в жизни», «Разве не правда, что она дала мне лучшие минуты жизни?». Есть здесь и время настоящее-будущее, когда герой представляет себе, что было бы, если б он не бросил Надежду: «Но, боже мой, что ж было бы дальше? Что, если бы я не бросил её? Какой вздор!» [1, с. 10, 12, 13, 14].

Сюжетные перипетии опять намечают противопоставление. Мы готовы осудить Николая за бессердечие, бесчеловечность. Но Бунин, знаток человеческой психологии, заставляет внимательно вчитаться в рассказ. Надежда начинает укорять Николая, произносит «обвинение» с «недоброй улыбкой», не может ему простить. Называет «тёмные аллеи» «всякими». Он же окунается в поэзию прежнего состояния: «Ах, как хороша ты была! Как горяча, как прекрасна!»... Его чувства не остыли, он жил ими всю жизнь, он переносил их на общения с другими женщинами, в т. ч. на ту, которая стала его женой. Настойчивые требования Надежды выслушать её заставляют его оправдываться. Он исповедуется, желая быть понятым и прощённым, рассказывает, как уже достаточно наказан жизнью: любимая жена изменила, бросила; обожаемый сын вырос негодяем, наглецом... Вот расплата за «обыкновенную историю», продолжением которой стала «обыкновенная, пошлая» повесть жизни.

Важным моментом в рассказе является столкновение двух концепций любви: «история пошлая, обыкновенная» [1, с. 12-13] и «лучшие, истинно волшебные минуты» [1, с. 14]. Примечательно, что понимаются и выражаются они одним героем - Николаем Алексеевичем. Причина тому - его живость, способность понимать жизнь как особую сферу бытия, где может сосуществовать нечто волшебное наряду с пошлым и обыкновенным. Герой этот, вплетаясь в пространство дороги жизни и становясь с ним единым целым, динамичен, в отличие от Надежды, жизнь которой находится на уровне стагнации, её сухой, 
«охозяйственный» мир горницы замкнут. Она живёт прошлым, не отпускает его, а с ним и Николая: «Как не было у меня ничего дороже вас на свете в ту пору, так и потом не было. Оттого-то и простить мне вас нельзя» [1, с. 13]. Она не способна на милосердие, не может и не хочет понять героя. Выраженные концепции тесно переплетаются, образуя сложное единство прозы жизни и поэзии любовного чувства. Важно, что эти проза и поэзия возникают на особом уровне - уровне реминисцентном, ассоциативном. Реминисценция «наводит на воспоминание о другом произведении», устанавливает так называемый «диалог культур». Именно поэтому важна узнаваемость реминисцентных образований для возникновения должных ассоциаций, которые направят читательское мышление на определённый культурный момент, потому что «текст живёт, только соприкасаясь с другим текстом (контекстом). Только в точке этого контакта текстов вспыхивает свет, освещающий и назад и вперед, приобщающий данный текст к диалогу» [3, с. 384].

В системе образов герои уравнены, они со-противопоставлены. Об этом свидетельствует организация кульминации рассказа: Надежда страдала в одиночестве, ожидая Николая, он страдал, потеряв с ней всё «самое дорогое, что имел в жизни». Сочувствуя Николаю Алексеевичу и осуждая Надежду, автор представляет свою «вненаходимость»: Бунин подчёркивает равенство их позиций одинаковым кульминационным жестом - поцелуем. Однако поцелуй не объединяет героев, а разлучает навек: «Она подошла и поцеловала у него руку, он поцеловал у неё». Для Надежды он по-прежнему барин, она же для него - женщина, заслуживающая уважения.

Нравственно-философскую проблематику произведения укрупняет анализ стихотворения, предполагающий диалог разных литературных родов. Автор оперирует их эстетическими возможностями, которые вытекают одно из другого, дополняя друг друга. «История пошлая, обыкновенная» отсылает нас к содержательной стороне стихотворения, а слово «обыкновенная», несомненно, коррелирует с названием «Обыкновенная повесть». Стоит заметить, что слова «история» и «обыкновенная» также отсылают нас и к роману И. А. Гончарова «Обыкновенная история», оказывающемуся ещё более прозаичным. Историей пошлой заканчивается история жизни героев, касающаяся как их совместного прошлого, так и прошлого самого героя. «Всё проходит, мой друг. Любовь, молодость - всё, всё», - констатирует Николай. И далее цитирует книгу Иова: «Как о воде протекшей будешь вспоминать» [1, с. 12]. Стихотворение вторит ему: «...и темно/ Осталось, для людей закрыто,/ Что было там говорено,/ И сколько было позабыто». Обращаясь к цитате из книги Иова, отметим её полную формулировку: «Тогда забудешь горе: как о воде протекшей, будешь вспоминать о нём» (Ветхий Завет, Кн. Иова, 11:16). В Книге Иова идёт спор о том, справедлив ли Бог, соответствуют ли наказания, которые получает человек при жизни, его грехам [16]. Неслучайно Надежда отвечает Николаю Алексеевичу: «Что кому бог даёт...» [1, с. 12]. Закончившаяся внезапно любовь, ушедшая молодость, «пошлое», «обыкновенное» течение жизни героев становится истинным горем, словно наказанием, посланным Богом. Бывшие влюблённые «безвинно страдают» [6, с. 414], лишь время способно притупить чувства грусти, сожаления о случившемся и неслучившем- 
ся, но также оно способно возрождать былые обиды и воспоминания, причиняющие боль. Но попробуем расширить реминисцентный контекст: «И яснее полдня пойдёт жизнь твоя; просветлеешь, как утро. И будешь спокоен, ибо есть надежда...» (Ветхий Завет, Кн. Иова, 11:1718). Необходимо забыть то горе, что причиняло и причиняет до сих пор боль, отпустить прошлое. Только тогда возможно почувствовать всю прелесть того мгновения жизни, что принесло счастье, оценить блаженство, ниспосланное человеку в дар: «Любовная встреча - это космическое событие» $[13$, с. 186]. Так включение строк из библейского писания помогает рассмотреть тему любви, развиваемую автором во всём цикле, не просто на уровне обыденных, бытовых отношений двух людей, но на уровне философского обобщения: «Любовь в большей степени не психологична, а онтологична. Поэтому и эстетический фокус Бунина не душа человека, а её сопряжение с мирозданием» [13, c. 187]. И действительно, писателя волнует скорее не психологическое состояние героев в минуты их переживаний, а взаимодействие человеческой души, человеческого чувства, и Любви как космической силы: «У Бунина нет мотивировок, рождение любовного чувства в них не нуждается, <...> но есть одна великая первопричина: могучая сила Эроса, разлитая в мироздании» [13, с. 185-186]. Любовь становится своего рода испытанием, благодаря которому человек проникается гаммой новых чувств и по-новому воспринимает этот мир.

О своей жизни герой говорит так: «Никогда я не был счастлив в жизни, не думай, пожалуйста». Жену любил без памяти (вероятно, надеясь получить от неё такую же горячую ответную любовь, которой одарила его в своё время Надежда), но она его бросила «ещё оскорбительней», чем он Надежду. Сын же вырос «негодяй, мот, без сердца», вероятно, так автор наказал героя. Однако герой осознаёт: «Думаю, что и я потерял в тебе самое дорогое, что имел в жизни» [1, с. 13]. Этот момент рассказа не уступает по силе чувств лирике. Николай понимает: «Разве неправда, что она дала мне лучшие минуты жизни? И не лучшие, а истинно волшебные!» [1, с. 14]. Именно минуты, мгновения, потому что «человек, по Бунину, находится в некоем заколдованном кругу тоски, пошлости, обыденщины. Лишь изредка улыбнётся ему счастье, а затем за ним снова захлопываются двери» [7, с. 327]. Далее герой вспоминает строку из стихотворения Огарёва, которая несёт в себе мощный эмоциональный, идейный, мотивный и даже композиционно-структурный посыл, резонансно отразившийся и на всей книге: «Кругом шиповник алый цвёл, стояли тёмных лип аллеи...». В этой строке «раскрывается» весенний пейзаж, момент встречи юных влюблённых, их «язык любви первоначальной», которые мы находим в стихотворении. Цитата, принадлежа стихотворению в плане идейно-художественном, переходит в рассказ и становится частью его художественной атмосферы. Тем самым стихотворение, являясь реально существующим художественным фактом, вплетается в ткань повествования, вносит часть реально-ирреального художественного мира. Примечательно, что Бунин сознательно изменяет цитируемый материал: вместо «стояла тёмных лип аллея» автор пишет «стояли тёмных лип аллеи». Так в тексте рассказа через множественное число возникает лейтмотив всего цикла, являющийся важной циклообразующей основой и пронизывающий всю книгу, создавая общую концептуальную атмосферу произведения. Как писал Бунин, «все рассказы 
этой книги только о любви, о её «тёмных» и чаще всего очень мрачных и жестоких аллеях». Герои исследуемого рассказа принимают мир односторонне. Надежда ограничила свой мир только материальным достатком, чтобы «получше пожить»: даёт деньги в рост, богатеет поэтому слывёт в округе «справедливой бабой», имеющей «ума палату». Такую сугубо практическую её деятельность одобряет кучер героя Клим, с которым героиня соотнесена в системе персонажей. Прагматическая идея победила прежнюю поэзию.

Николай Алексеевич стыдится своей душевной памяти, хотя именно она раскрывает лучшие, волшебные минуты его характера и жизни. Изменённое слово в строке стихотворения Н. Огарёва («кругом шиповник алый цвёл» вместо «вблизи») говорит о невозможности соединения сердец: она для него только та самая Надежда, содержательница постоялой гостиницы...»

Оба героя недостойны быть награждёнными счастьем. Счастье, по Бунину, достояние немногих, оно даётся избранным, тем, у кого физическая и духовная сила и красота проявляются вместе.

Так уже в заглавном рассказе отмечается двоякая природа «тёмных аллей». Это выражено в разном отношении героев к прошлому: Николай вспоминает об этом как о волшебных минутах, погружается в эти «аллеи», «алый шиповник»; Надежда же припоминает «стихи про всякие «тёмные аллеи» с недоброй улыбкой [1, с. 12]. И вся книга пронизана диалектическим сочетанием любви и несчастья, сопряжённым в сознании автора как неразрывно связанные элементы бытия.

Таким образом, реминисцентные переклички рассказа И. А. Бунина «Тёмные аллеи» со стихотворением Н. П. Огарёва «Обыкновенная повесть» становятся лейтмотивом сюжетно-композиционной организации, совмещающей принципы организации как эпических, так и лирических циклов, позволяющие увидеть в заглавном рассказе победу поэзии чувства над прозой жизни.

\section{Литература}

1. Бунин И. А. Тёмные аллеи / Вступит. ст. О. Михайлова. - М.: Худож. лит., 1991. $252 \mathrm{c}$.

2. Анисимова Е. Е., Анненкова Е. С. На пересечении традиций // Вестник ун-та им. А. Нобеля. Сер. Филологические науки. 2017. № 2 (14). С. 3-37.

3. Бахтин М. М. Эстетика словесного творчества. - М.: Искусство, 1986. 445 с.

4. Бердяев Н. А. Дух и реальность // Философия свободного духа. - М.: Республика, 1994. 480 с. [Электронный ресурс] // Библиотека Якова Кротова (сайт). URL http://krotov.info/library/02_b/ berdyaev/1937_034_05.html (Дата обращения 30.10.2020).

5. Богданова О. В., Лю Ц. (КНР). Пушкинский интертекст в рассказе И. Бунина
«Антигона» // Культура слова: эл.научный журнал. 2019. № 2(3). URL https://jword.ru/ archive/3/78 (дата обращения: 09.12.2020)

6. Бонами Т. М. Творчество И. А. Бунина в контексте русской культуры. М.: б. и., 2003. 130 с.

7. Волков А. А. Проза Ивана Бунина. М.: Московский рабочий, 1969. 448 с.

8. Выготский Л. С. Психология искусства / Общ. ред. В.В. Иванова, коммент. Л. С. Выготского и В. В. Иванова, вступит. ст. А. Н. Леонтьева. - М.: Искусство, 1986. $573 \mathrm{c}$.

9. Марченко Т. В. Диалогическая поэтика любовной прозы И. А. Бунина: резервы интерпретации // Известия РАН. Сер. лит. и яз. Т. 73. № 2. С. 3-19.

10. Панченко Т. Ф., Нечаева Д. И. Книга 
И. А. Бунина «Тёмные аллеи» как метажанровое единство» // Известия Восточного института. 2016. № 4 (32). С. 10-21.

11. Пономарёв Е. Интертекст «Тёмных аллей»: растворение новеллы в бунинских поздних работах [Электронный ресурс] // Новое литературное обозрение. 2018. № 2. // Новое литературное обозрение (сайт). URL https://www.nlobooks.ru/magazines/ novoe_literaturnoe_obozrenie/150_ nlo_2_2018/article/19577/ (Дата обращения 09.12.2020).

12. Пращерук Н. В. Диалоги с русской классикой: о прозе И. А. Бунина: монография. - Екатеринбург: Гуманитар. ун-т, 2012. $141 \mathrm{c}$.

13. Сливицкая О. В. «Повышенное чув- ство жизни»: мир Ивана Бунина. - М.: Российск. гос. гуманит. ун-т, 2004. 270 с.

14. Фоменко И. В. Лирический цикл как метатекст // Лингвистические аспекты исследования литературно-художественных текстов. - Калинин: КГУ, 1979. 165 с. C. $112-128$.

15. Харитонова О. Н. Я иду на урок [Электронный ресурс] // Журнал «Литература» (сайт). URL http://lit.1september.ru/ article.php?ID=200602109 (Дата обращения 30.10.2020).

16. Эпштейн М. Н. Теология Книги // Звезда. 2006. № 12. [Электронный ресурс] // Сетевое издание «Горький». URL http:// magazines.russ.ru/zvezda/2006/12/e15.html (Дата обращения 30.10.2020).

\section{Tatiana F. PANCHENKO}

Ph. D. (in Pedagogy), Associate Professor, Russian Language and Literature Department, Oriental Institute - School of Regional and International Studies, Far Eastern Federal University (Vladivostok, Russia)

E-mail: panchenko.tf@dvgu.ru

\section{A. Bunin's short story "Dark Alleys" and N. P. Ogarev's poem "An Ordinary Story": intertextual dialogue}

UDC 82.02/09

doi: dx.doi.org/10.24866/2542-1611/2020-3/31-40

The subject of the research is reminiscences of I. Bunin's short Bunin "Dark Alleys", story "Dark Alleys" with N. Ogarev's poem "An Ordinary story”. N. Ogarev "An Ordinary Having considered the plot of the story, we identified a way of Story", binary / gender opposition of the system of characters, a leitmotif and a system of accompanying motives that are implemented in other works and expand its problems. The story is analyzed in the context of a precedent text - N. Ogarev's poem "An Ordinary Story". Reminiscences at the level of the title, events of the plot/plot, meeting - parting - memories, and the characters' relationship motive. to the dual nature of the image of "dark alleys" are noted. The development of the dialectical combination of love and misery, life and being is analyzed. The author reveals the motivic structure of the plot, the binary opposition of the character system, and the chronotope. It is proved that the intertextual dialogue of works of different literary types makes it possible to discover new philosophical meanings. The methodological basis is the concept of "dialogue of cultures" developed by M. M. Bakhtin and the teaching of Y. M. Lotman about the integrity of the prose structure. It is proved that the analyzed story is characterized by a combination of epic and lyrical techniques of composition about a certain meta-genre of "Dark Alleys". 
For citation: Panchenko T. F. I. A. Bunin's short story "Dark Alleys" and N. P. Ogarev's poem "An Ordinary Story": intertextual dialogue // Oriental Institute Journal. 2020. № 3. P. 31-40. doi: dx.doi.org/10.24866/2542$1611 / 2020-3 / 31-40$

\section{References}

1. Bunin I. A. Tyomnye allei / Vstupit. st. O. Mikhajlova. - M.: KHudozh. lit., 1991. $252 \mathrm{~s}$.

2. Anisimova E. E., Annenkova E. S. Na peresechenii traditsij // Vestnik un-ta im. A. Nobelya. Ser. Filologicheskie nauki. 2017. № 2 (14). S. 3-37.

3. Bakhtin M. M. EHstetika slovesnogo tvorchestva. - M.: Iskusstvo, 1986. $445 \mathrm{~s}$.

4. Berdyaev N. A. Dukh i real'nost' // Filosofiya svobodnogo dukha. - M.: Respublika, 1994. 480 s. [EHlektronnyj resurs] // Biblioteka YAkova Krotova (sajt). URL http://krotov.info/library/02_b/ berdyaev/1937_034_05.html obrashheniya 30.10.2020).

(Data

5. Bogdanova O. V., Lyu TS. (KNR). Pushkinskij intertekst $\mathrm{v}$ rasskaze I. Bunina «Antigona» // Kul'tura slova: ehl.nauchnyj zhurnal. 2019. № 2(3). URL https://jword.ru/ archive/3/78 (data obrashheniya: 09.12.2020)

6. Bonami T. M. Tvorchestvo I. A. Bunina v kontekste russkoj kul'tury. M.: b. i., 2003. $130 \mathrm{~s}$.

7. Volkov A. A. Proza Ivana Bunina. - M.: Moskovskij rabochij, 1969. $448 \mathrm{~s}$.

8. Vygotskij L. S. Psikhologiya iskusstva / Obshh. red. V.V. Ivanova, komment. L. S. Vygotskogo i V. V. Ivanova, vstupit. st. A. N. Leont'eva. - M.: Iskusstvo, 1986. 573 s.

9. Marchenko T. V. Dialogicheskaya poehtika lyubovnoj prozy I. A. Bunina: rezervy interpretatsii // Izvestiya RAN. Ser. lit. i yaz. T. 73. № 2. S. 3-19.
10. Panchenko T. F., Nechaeva D. I. Kniga I. A. Bunina «Tyomnye allei» kak metazhanrovoe edinstvo" // Izvestiya Vostochnogo instituta. 2016. № 4 (32). S. 10-21.

11. Ponomaryov E. Intertekst «Tyomnykh allej»: rastvorenie novelly $\mathrm{v}$ buninskikh pozdnikh rabotakh [EHlektronnyj resurs] // Novoe literaturnoe obozrenie. 2018. № 2. // Novoe literaturnoe obozrenie (sajt). URL https://www.nlobooks.ru/magazines/novoe literaturnoe_obozrenie/150_nlo_2_2018/ article/19577/ (Data obrashheniya 09.12.2020).

12. Prashheruk N. V. Dialogi s russkoj klassikoj: o proze I. A. Bunina: monografiya. - Ekaterinburg: Gumanitar. un-t, 2012. 141 s.

13. Slivitskaya O. V. «Povyshennoe chuvstvo zhizni»: mir Ivana Bunina. - M.: Rossijsk. gos. gumanit. un-t, 2004. 270 s.

14. Fomenko I. V. Liricheskij tsikl kak metatekst // Lingvisticheskie aspekty issledovaniya literaturno-khudozhestvennykh tekstov. - Kalinin: KGU, 1979. 165 s. C. 112128.

15. KHaritonova O. N. YA idu na urok [EHlektronnyj resurs] // ZHurnal «Literatura» (sajt). URL http://lit.1september.ru/article. php? $\mathrm{ID}=200602109 \quad$ (Data obrashheniya 30.10.2020).

16. EHpshtejn M. N. Teologiya Knigi // Zvezda. 2006. № 12. [EHlektronnyj resurs] // Setevoe izdanie «Gor'kij». URL http:// magazines.russ.ru/zvezda/2006/12/e15.html (Data obrashheniya 30.10.2020). 